Palavras chave:

Estoque de nutrientes

Floresta nativa

Ciclagem de nutrientes

Histórico:

Recebido 06/09/201 I

Aceito 02/10/2014

Keywords:

Nutrients stock

Native forest

Nutrient cycling

Correspondência: hamiltonvogel@unipampa.edu.br

DOI: I0. I590/0 I047760201521021328

\section{MICRONUTRIENTES NA BIOMASSA ACIMA DO SOLO EM UMA FLORESTA ESTACIONAL SUBTROPICAL}

RESUMO: Na biomassa acima do solo de uma floresta nativa ou plantada, estão estocadas grandes quantidades de nutrientes, com poucos trabalhos encontrados na literatura, principalmente com micronutrientes. Conduziu-se este trabalho com o objetivo principal de quantificar a biomassa e os micronutrientes estocados na biomassa, acima do solo, em uma Floresta Estacional Subtropical, em Itaara-RS, Brasil. Para a quantificação da biomassa, foram abatidas 20 árvores distribuídas em cinco classes de diâmetros. As árvores abatidas foram separadas nas frações: madeira do fuste, casca do fuste, galhos e folhas. Nas amostras da biomassa, foram determinados os teores totais de $\mathrm{B}, \mathrm{Cu}, \mathrm{Fe}$, $\mathrm{Mn}$ e $\mathrm{Zn}$. O estoque de micronutrientes na biomassa, para cada componente foi obtido com base na biomassa seca estimada, multiplicada pelo teor de nutrientes. A produção total estimada de biomassa acima do solo foi de $210,0 \mathrm{Mg} \cdot \mathrm{ha}^{-1}$. Nessa estimativa, os galhos corresponderam a $48,8 \%$, a madeira do fuste $43,3 \%$, a casca do fuste $5,4 \%$, e as folhas 2,4\%. Os menores teores de B, Cu, Fe e $\mathrm{Mn}\left(\mathrm{mg} \cdot \mathrm{kg}^{-1}\right)$ estão na madeira do fuste, com exceção do Zn; nos galhos e na madeira, estão os maiores estoques de B, Cu, Fe e Mn $\left(\mathrm{kg} \cdot \mathrm{ha}^{-1}\right)$. Nos galhos, folhas e cascas, está estocada a maior parte dos micronutrientes, apontando a importância destes de permanecerem sobre o solo.

\section{ABOVE GROUND BIOMASS MICRONUTRIENTS IN A SEASONAL SUBTROPICAL FOREST}

ABSTRACT: In the above ground biomass of a native forest or plantation are stored large quantities of nutrients, with few studies in the literature, especially concerning micronutrients. The present work aimed to quantify the micronutrients in above ground biomass in a Seasonal Subtropical forest in Itaara-RS, Brazil. For the above ground biomass evaluation, 20 trees of five different diameter classes were felled. The above ground biomass was separated in the following compartments: stem wood, stem bark, branches and leaves. The contents of $\mathrm{B}, \mathrm{Cu}, \mathrm{Fe}, \mathrm{Mn}$ and $\mathrm{Zn}$ in the biomass samples were determined. The stock of micronutrients in the biomass for each component was obtained based on the estimated dry biomass, multiplied by the nutrient content. The total production of

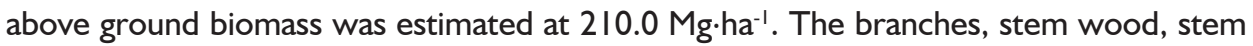
bark and leaves corresponded to $48.8,43.3,5.4$ and $2.4 \%$ of the above ground biomass. The lower levels of $\mathrm{B}, \mathrm{Cu}, \mathrm{Fe}$ and $\mathrm{Mn}$ are in stem wood, except for $\mathrm{Zn}$; in the branches and trunk wood are the largest stocks of $\mathrm{B}, \mathrm{Cu}, \mathrm{Fe}$ and $\mathrm{Mn}$. In the branches, leaves and trunk bark are stored most micronutrients, pointing to the importance of these to remain on the soil.

\footnotetext{
' Universidade Federal do Pampa - São Gabriel, Rio Grande do Sul, Brasil

2 Universidade Federal de Santa Maria - Santa Maria, Rio Grande do Sul, Brasil

${ }^{3}$ Albert-Ludwigs-Universität Freiburg - Freiburg, Alemanha
} 


\section{INTRODUÇÃO}

A região do município de ltaara na região central do Rio Grande do Sul, onde se encontra o estudo, tem forte tradição agropecuária, gerando grandes impactos em seus ecossistemas nativos. Nessas regiões, é comum a remoção de áreas da floresta para o estabelecimento de cultivos agrícolas, enquanto a fertilidade do solo permita colheitas satisfatórias, e, posteriormente, o abandono da agricultura e a abertura de novas áreas de floresta, levando a formação de um mosaico de diversos estágios sucessionais na paisagem, com diferentes graus de degradação (BRUN et al., 2010).

Assim, em um ecossistema florestal, existe uma grande dinâmica na produção de biomassa. $O$ acúmulo de biomassa é afetado por fatores ambientais como luz, temperatura, concentração de $\mathrm{CO}_{2}$ do ar, umidade e fertilidade do solo, e doenças e, também, por fatores de cada planta, como idade, estrutura e disposição das folhas, distribuição e comportamento dos estômatos, teor de clorofila, entre outros (KRAMER; KOZLOWSKI, 1972).

$\mathrm{Na}$ biomassa acima do solo de uma floresta nativa ou plantada, estão estocadas grandes quantidades de nutrientes. De acordo com Landsberg (1986), as reservas de nutrientes nas florestas estão presentes nos vários componentes das árvores, no solo e na vegetação de sub-bosque, sendo que, do montante, somente uma pequena fração está em fluxo entre os vários compartimentos do sistema.

Nas zonas temperadas, uma grande porção de material orgânico e de nutrientes disponíveis está sempre situada nos solos, ao passo que nos trópicos uma porcentagem muito maior está localizada na biomassa, e é reciclada rapidamente no interior das florestas (ODUM; BARRETT, 2008).

Em relação à estimativa da biomassa de uma floresta nativa, esta pode variar muito com o tipo de floresta e local onde se encontra. Em florestas Estacional Decidual, Ombrófila Mista, tropical amazônica, tropicais asiáticas e temperada na Alemanha (Fagus silvatica), as estimativas das biomassas totais foram de 186,25 Mg.ha-1 (BRUN, 2004), 2 l 0,4 Mg.ha-1 (CALDEIRA, 2003), 324,0 Mg.ha-1 (HIGUCHI et al., 1998), $225 \mathrm{Mg} \cdot \mathrm{ha}^{-1}$ (BROWN et al., 199l) e $313 \mathrm{Mg} \cdot \mathrm{ha}^{-1}$ (OTTO, 1994), respectivamente.

Dessa maneira, os estudos envolvendo a quantificação da biomassa constituem a base para o conhecimento do estoque e dinâmica dos nutrientes na floresta, e de como manejar esses ecossistemas de forma sustentável, podendo-se destacar a quantificação da ciclagem de nutrientes, a quantificação de biomassa para fins industriais e energéticos, e como base de informação para estudos de sequestro de carbono (SILVEIRA et al., 2008), com grande importância para a tomada de decisões no manejo dos recursos florestais.

$\mathrm{Na}$ região da floresta Estacional Subtropical, no estado do RS, os estudos com ciclagem de nutrientes são escassos, principalmente com relação aos micronutrientes. Nesse contexto, neste trabalho, objetivou-se, principalmente, quantificar a biomassa acima do solo das árvores e os micronutrientes $(B, C u, F e$, $\mathrm{Mn}$ e $\mathrm{Zn}$ ), estocados nessa biomassa, em um fragmento de Floresta Estacional Subtropical em Itaara-RS, Brasil.

\section{MATERIAL E MÉTODOS}

\section{Caracterização da área do estudo}

O trabalho foi realizado em uma fazenda da Fundação da Brigada Militar, no município de Itaara, estado do Rio Grande do Sul, Brasil. O município de Itaara está localizado na Serra de São Martinho, na região fisiográfica do Planalto Médio. Verifica-se, na Figura I, a localização do município de Itaara no estado do Rio Grande do Sul, e da área experimental com as

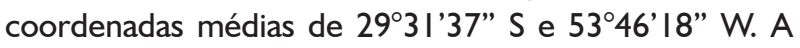
altitude média do local é de $400 \mathrm{~m}$. A área escolhida para o estudo, foi um fragmento de, aproximadamente, 60 hectares, com aspecto homogêneo de paisagem e solo, representativo do local. No local foi realizado um inventário das espécies florestais detalhado na sequência.

A região em que o município de Itaara está inserido apresenta clima Cfa (Classificação climática de Köppen). De acordo com a Plataforma de Coleta de Dados do INPE de São Martinho da Serra-RS (estação mais próxima da área experimental), no período compreendido entre 2003 e 2006, a temperatura média foi de $19,6^{\circ} \mathrm{C}$, e, a precipitação anual de $1520,5 \mathrm{~mm}$, para esse período. $O$ solo da região é caracterizado como Neosolo Litólico eutrófico típico (STRECK et al., 2008). Essa classe de solos é descrita pela Empresa Brasileira de Pesquisa Agropecuária - EMBRAPA (1999) como "solos com horizonte $\mathrm{A}$ ou $\mathrm{O}$ hístico com menos de $40 \mathrm{~cm}$ de espessura, assente diretamente sobre a rocha ou sobre um horizonte $\mathrm{C}$ ou $\mathrm{Cr}$ ou sobre material com $90 \%$ ou mais de sua massa, constituída por fragmentos de rocha com diâmetro maior que $2 \mathrm{~mm}$ (cascalhos, calhaus e matacões)." Ainda, conforme a EMBRAPA (1999), esses solos têm alta saturação de bases $(V \geq 50 \%)$ em todos os horizontes, o que também foi constatado pela 
análise de solo do local, sendo o mesmo considerado de fertilidade média a alta. Também é importante ressaltar, que no local do estudo, o solo é bastante raso, ficando em torno de $30 \mathrm{~cm}$ de profundidade.
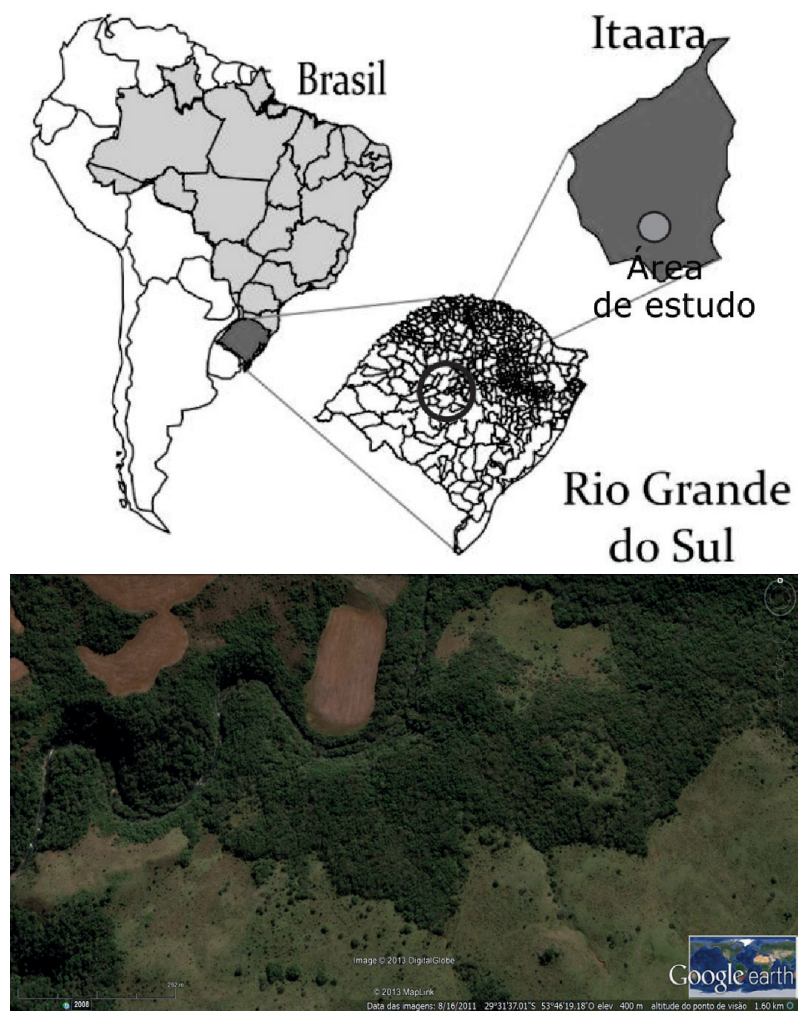

FIGURA 1 Localização da área de estudo, no município de Itaara, na região central do estado do Rio Grande do Sul, Brasil. Imagem orbital no site do Google Earth $\circledast$ (2013).

FIGURE 1 Localization of the city of Itaara and the experimental area in the State of the Rio Grande do Sul, Brazil. Orbital image from the Google Earth $\circledast$ (2013) website.

Em relação à vegetação arbórea, para a realização do inventário, foram demarcadas no local da avaliação da biomassa, 12 parcelas de $10 \times 10 \mathrm{~m}$ cada, equidistantes 10 metros em linha, onde foram medidos todos os DAPs (diâmetro à altura do peito) das árvores com CAP (circunferência à altura do peito) $\geq 10,0$ $\mathrm{cm}$, e todas as alturas dos indivíduos e a identificação das espécies arbóreas. Ao todo foram medidas e identificadas um total de 506 árvores no inventário. Conforme os resultados desse inventário, quanto à composição florística, foram encontradas 52 espécies, divididas em 24 famílias, destacando-se as famílias Leguminosae, Euphorbiaceae e Sapindaceae, em razão de seus representantes apresentarem os maiores valores no Índice de Valor de Importância-IVI (estimadores da importância ecológica de um táxon (espécie, família, etc) dentro de uma comunidade florestal); a família com maior número de representantes foi a Myrtaceae, porém todos eles com baixos valores nos índices relativos; as espécies de maior destaque foram a Parapiptadenia rigida e a Sebastiana commersoniana, em razão de seus altos valores no IVI, que totalizam 48,73\%; a Parapiptadenia rigida apresentou o maior valor de Dominância (área basal de determinada espécie por unidade de área) e a Sebastiana commersoniana a maior densidade e frequência. Quanto à idade e estágio de desenvolvimento, conforme as informações da Fundação da Brigada Militar, responsável pelo local, estima-se que a floresta tenha em torno de 70 anos de idade, e esteja em estágio secundário avançado de sucessão.

\section{Amostragem e análise dos dados}

Para a amostragem dos dados, de acordo com as informações obtidas do inventário, foram determinadas cinco classes de diâmetro, com intervalo de classe igual a 10,36, de maneira a abranger a maior variação possível do povoamento. $O$ intervalo de classe foi obtido conforme equação $\mathrm{I}$, onde $\mathrm{h}=$ amplitude do intervalo de classes, $\mathrm{H}=$ amplitude total (DAPmáximo - DAPmínimo) (DAP: diâmetro a altura do peito) e $\mathrm{K}=$ número de classes.

$h=H / K$

As árvores foram escolhidas, aleatoriamente, em função das cinco classes de diâmetro. No total, foram abatidas vinte árvores, distribuídas nas classes de diâmetros da seguinte forma: $3,2-13,5 \mathrm{~cm}$ com II árvores, 13,6 - 23,9 cm com 4 árvores, 24,0 - 33,6 cm com 3 árvores, 33,7 - 44,6 cm com I árvore, 44,7 $55,0 \mathrm{~cm}$ com I árvore. Essa distribuição da amostragem das árvores foi realizada em função da distribuição diamétrica em forma de J invertido, típica de florestas nativas, onde a frequência das maiores árvores vai diminuindo, conforme o aumento da classe de diâmetro, com pequena suficiência amostral nas maiores classes, razão pela qual foi escolhida apenas uma árvore nas duas maiores classes. Nessa amostragem não foram consideradas as lianas e as árvores mortas. Todas as árvores foram cortadas e cubadas conforme o método de Smalian, descrito por Finger (1992), obtendo-se os DAPs e as alturas totais e dos troncos. Após a cubagem, as árvores foram separadas nos componentes, madeira do fuste, casca do fuste, galhos e folhas. Foi estabelecido como fuste, a seção da base do tronco até a primeira 
bifurcação (também conhecida como “forquilha”), sendo o restante considerado como galhos. Em função da grande variabilidade morfológica das árvores, os galhos amostrados não foram subdivididos por diâmetro. $\mathrm{Na}$ sequência, cada componente da árvore foi separado e pesado na sua totalidade, utilizando-se uma balança de gancho. Para as amostras de madeira e casca do fuste, foram retirados três discos do tronco, a $0,10 \mathrm{~cm}$, na metade e no final da altura do fuste, para evitar as diferenças entre as proporções de alburno e cerne das árvores em função da altura. Nesses discos foi separada a casca da madeira, estimando-se, assim, a quantidade de casca de todo o fuste. Para folhas e galhos foram obtidas amostras compostas após a pesagem dos mesmos, onde foram homogeneizados sobre uma lona preta. As coletas de biomassa foram obtidas no período de maio a julho de 2005. A estimativa da biomassa de cada componente das árvores, foi obtida pelo uso da equação 2 , onde $\log y=$ logaritmo do componente; $b_{0}$ e $b_{1}=$ coeficientes da equação; log DAP = logaritmo do diâmetro da árvore a I,30 m de altura.

$\log (y)=b_{0}+b_{1} \cdot \log (D A P)$

A equação 2 utilizada foi selecionada em função do ajuste satisfatório da estimativa da biomassa acima do solo para os componentes estudados. Para determinação da umidade e análise química dos nutrientes em laboratório, em cada componente da biomassa, foi retirada uma amostra composta de aproximadamente $300 \mathrm{~g}$, para a obtenção do peso úmido. Essas amostras foram secas em estufa a $75^{\circ} \mathrm{C}$ até atingir peso constante, obtendo-se o peso seco. $\mathrm{Na}$ sequência, o material foi moído em moinho do tipo Willey para a realização das análises químicas. Foram determinados os teores totais de $\mathrm{B}, \mathrm{Cu}, \mathrm{Fe}, \mathrm{Mn}$ e $\mathrm{Zn}$, segundo a metodologia descrita por Miyazawa et al. (1999) e Tedesco et al. (1995). O estoque de nutrientes na biomassa $\left(\mathrm{kg} \cdot \mathrm{ha}^{-1}\right)$, para cada componente foi obtido pela média da biomassa das parcelas do inventário, multiplicando-se a biomassa de cada componente pelo teor de cada nutriente.

\section{RESULTADOS E DISCUSSÃO}

\section{Estimativa da biomassa}

Nota-se, na Tabela I, que foi obtido um ajuste satisfatório na estimativa da biomassa acima do solo para os componentes estudados, constatado pelos valores elevados do coeficiente de determinação ajustados
( $R^{2}$ aj.) e os baixos erros padrão percentual da estimativa (Syx). Essa equação utilizada no trabalho, já apresentou boa estimativa da biomassa para florestas plantadas de Acácia-negra, Eucalipto e Pinus (BARICHELLO, 2003), o que, também, foi verificado nesse estudo, dentro das condições observadas, sendo rara a disponibilidade de artigos na literatura com estimativa de biomassa de florestas nativas por equações, o que dificulta a comparação com outros modelos disponíveis já utilizados. Brown (1997) recomenda que, sempre que possível, devem ser desenvolvidas equações locais de biomassa, ou ao menos, que algumas árvores sejam abatidas para testar se a equação utilizada é adequada, o que foi feito no presente estudo.

TABELA 1 Localização da área de estudo, no município de Itaara, na região central do estado do Rio Grande do Sul, Brasil. Imagem orbital no site do Google Earth ${ }^{\circledR}(2013)$.

TABLE 1 Localization of the city of Itaara and the experimental area in the State of the Rio Grande do Sul, Brazil. Orbital image from the Google Earth ${ }^{\circledR}(2013)$ website.

\begin{tabular}{|c|c|c|c|c|c|c|}
\hline Componente & $\mathrm{b}_{0}$ & $\mathrm{~b}_{1}$ & $\mathrm{R}^{2} \mathrm{aj}$. & $\begin{array}{l}\text { Syx } \\
(\%)\end{array}$ & $\begin{array}{l}\text { Biomassa } \\
\text { estimada }\end{array}$ & $(\%)$ \\
\hline $\begin{array}{l}\text { Madeira - } \\
\text { Fuste }\end{array}$ & $-0,785273$ & 2,029922 & 0,98 & 8,1 & 91,0 & 43,4 \\
\hline $\begin{array}{l}\text { Casca - } \\
\text { Fuste }\end{array}$ & $-1,547650$ & 1,917776 & 0,94 & 5,0 & 11,4 & 5,4 \\
\hline Galhos & $-1,959654$ & 2,935550 & 0,91 & 8,1 & 102,4 & 48,8 \\
\hline Folhas & $-2,322212$ & 2,250508 & 0,88 & 9,9 & 5,1 & 2,4 \\
\hline $\begin{array}{l}\text { Biomassa } \\
\text { total }\end{array}$ & $-0,882390$ & 2,409594 & 0,98 & 8,0 & 210,0 & 100 \\
\hline
\end{tabular}

A média da produção total da biomassa acima do solo estimada pela equação foi de $210,0 \mathrm{Mg} \cdot \mathrm{ha}^{-1}$ (Tabela I). Nessa estimativa, os galhos corresponderam a $48,8 \%$ da biomassa acima do solo, seguidos da madeira do fuste com 43,4\%, 5,4\% para a casca do fuste, e 2,4\% para as folhas, estabelecendo-se a seguinte ordem de quantidade: galhos $>$ madeira do fuste $>$ casca do fuste $>$ folhas. A proporção maior da biomassa dos galhos em relação ao fuste das árvores, deve-se, em parte, pela metodologia empregada, na qual foi considerado como galhos o ponto a partir da primeira bifurcação do tronco, o que pode gerar uma superestimativa para a biomassa dos galhos e uma subestimação da biomassa do fuste. Caldeira et al. (2006) em uma Floresta Ombrófila Mista Montana em General Carneiro/PR, na avaliação da biomassa, consideraram como galhos todo o material lenhoso localizado acima do início da copa viva, o que pode ter causado uma superestimação da biomassa de galhos e uma subestimação da biomassa 
de troncos, estimando uma biomassa total acima do solo das árvores com DAP $\geq 10 \mathrm{~cm}$, de $210,4 \mathrm{Mg} \cdot \mathrm{ha}^{-1}$, assim distribuída: galhos $(45,3 \%)>$ madeira do fuste $(4 \mathrm{I}, 1 \%)>$ casca $(10,3 \%)>$ folhas $(2,4 \%)$. Watzlawick et al. (20I2), encontraram em um fragmento florestal de Floresta Ombrófila Mista Montana também na região do município de General Carneiro, PR, uma biomassa acima do solo de 250,90 Mg·ha ${ }^{-1}$. Já, na região de AraucáriaPR, também em Floresta Ombrófila Mista, Socher et al. (2008), estimaram uma biomassa acima do solo de 195 $M g \cdot h a^{-1}$. Em uma Floresta Estacional Decidual secundária, com cerca de 53 anos, em Santa Tereza-RS, Brun (2004) encontrou uma biomassa acima do solo de 157,6 $\mathrm{Mg} \mathrm{ha}^{-1}$, sendo essa formada a maior parte pela madeira do fuste $(52,41 \%)$ seguido pelos galhos $(28,4 \%)$, caracterizando uma floresta ainda em formação. Golley et al. (1978), em uma Floresta Tropical Úmida no Panamá, constataram realidades bastante diferentes, de acordo com o local de amostragem, encontrando uma biomassa acima do

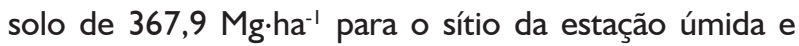
263,5 Mg.ha-1 para o sítio da estação seca. Na floresta tropical amazônica, Higuchi et al. (1998), estimaram a biomassa acima do solo em $324,0 \mathrm{Mg} \cdot \mathrm{ha}^{-1}$, com os troncos correspondendo a $65,6 \%$, e a copa a $34,4 \%$, a qual foi dividida em galhos grossos (diâmetro $>1,0 \mathrm{~cm}$ ) com $17,8 \%$, galhos finos $14,5 \%$, folhas $2,03 \%$, e flores/ frutos $0,01 \%$.

\section{Micronutrientes na Biomassa}

Quanto aos teores de micronutrientes na biomassa, observa-se, na Tabela 2, que o Boro apresentou os maiores teores nas folhas, com os menores teores na madeira, ficando todos os componentes, com exceção da madeira, dentro do intervalo de necessidades das plantas superiores, recomendado por Larcher (2000), que varia de 10 a $40 \mathrm{mg} \cdot \mathrm{kg}^{-1}$. Brun et al. (2010) também encontraram nas folhas do estrato arbóreo, as maiores concentrações de Boro, em uma floresta Estacional Decidual secundária em Santa Tereza-RS. Caldeira et al. (2006), também verificaram em uma Floresta Ombrófila Mista Montana em General Carneiro/PR, que o B apresentou os maiores teores médios na biomassa da fração folhas de espécies do estrato arbóreo.

Também para o cobre, o menor teor foi obtido na madeira, ficando o maior nas folhas. De acordo com Larcher (2000), a necessidade de cobre por parte das plantas varia entre 5,0 e 10,0 mg kg-I. Conforme Larcher (2000) e Malavolta (1985), o acúmulo preferencial de Cu se dá nas partes lenhosas das plantas, o que não foi
TABELA 2 Teores de micronutrientes na biomassa acima do solo nos componentes das árvores de uma Floresta Estacional Subtropical em Itaara-RS, Brasil.

TABLE 2 Micronutrients content in the above ground biomass components in trees of a Seasonal Subtropical forest, in Itaara-RS, Brazil.

\begin{tabular}{lccccc}
\hline \multicolumn{1}{c}{ Componente } & $\mathrm{B}$ & $\mathrm{Cu}$ & $\mathrm{Fe}$ & $\mathrm{Mn}$ & $\mathrm{Zn}$ \\
\hline & \multicolumn{5}{c}{$\mathrm{mg} \cdot \mathrm{kg}^{-1}$} \\
\cline { 2 - 6 } Madeira - Fuste & 4,93 & 2,96 & 49,62 & 48,97 & 47,86 \\
Casca - Fuste & 15,85 & 6,89 & 305,80 & 159,14 & 20,08 \\
Galhos & 11,71 & 6,94 & 136,64 & 184,64 & 13,48 \\
Folhas & 30,10 & 7,76 & 196,11 & 348,71 & 20,12 \\
\hline Total & 15,65 & 6,14 & 172,04 & 185,37 & 25,38 \\
\hline
\end{tabular}

observado neste trabalho. Em estudo com a fração folhas de 23 espécies nativas de diferentes estágios sucessionais em uma área de Floresta Ombrófila Densa no litoral do Paraná, Boeger et al. (2005) relataram teores de $\mathrm{Cu}$ médios de $5,9 \mathrm{mg} \cdot \mathrm{kg}^{-1}$ em estágio sucessional inicial, $7,2 \mathrm{mg} \cdot \mathrm{kg}^{-1}$ em estágio intermediário e $8,1 \mathrm{mg} \cdot \mathrm{kg}^{-1} \mathrm{em}$ estágio avançado, ficando esses valores próximos aos do presente estudo. Os menores teores de ferro ocorreram na madeira seguida dos galhos. $\mathrm{Na}$ casca foi constatado o maior teor de ferro, o que também foi verificado por Brun et al. (2010). Segundo Floss (2008), o teor de ferro nos tecidos vegetais está em torno de $100 \mathrm{mg} \cdot \mathrm{kg}^{-1}$, ficando abaixo do encontrado no presente estudo. Boeger et al. (2005) em uma Floresta Ombrófila Densa no litoral do Paraná, no estágio successional avançado, encontraram, nas folhas, um teor de ferro abaixo do encontrado neste estudo, de $62,5 \mathrm{mg} \cdot \mathrm{kg}^{-1}$ de ferro. Para o manganês, os maiores teores ocorreram nas folhas que, segundo Malavolta (1985) é formador da clorofila e dos cloroplastos, ativador de diversas enzimas, participando do transporte eletrônico na fotossíntese. Larcher (2000) aponta que, a necessidade de Mn na maioria das plantas lenhosas situa-se entre 30 e $50 \mathrm{mg} \cdot \mathrm{kg}^{-1}$, valores estes bem abaixo dos encontrados nas folhas, galhos e casca do tronco deste trabalho. Já, Boeger et al. (2005) encontraram em uma Floresta Ombrófila Densa no litoral do Paraná, no estágio successional avançado, teores nas folhas de $216,8 \mathrm{mg} \cdot \mathrm{kg}^{-1}$ de $\mathrm{Mn}$, valores menores ao deste estudo. Já, os teores de zinco foram maiores para a madeira, e menores para os galhos. Para todos os componentes, os teores de zinco ficaram dentro do intervalo de necessidades para as plantas, estabelecido por Larcher (2000), o qual é de 10 a $50 \mathrm{mg} \cdot \mathrm{kg}^{-1}$.

De acordo com Gonçalves e Valeri (200I), os teores de micronutrientes são maiores nas partes 
da planta metabolicamente mais ativa, como folhas e brotações, decorrentes de seus envolvimentos em reações enzimáticas e compostos bioquímicos de transferência de energia; já, os menores teores são encontrados na madeira. Esses resultados também foram observados neste trabalho, com exceção do $Z n$ que teve o maior teor na madeira.

Com base nos resultados das concentrações dos micronutrientes estudados, e as faixas indicadas como ideais para o crescimento das plantas citadas pela literatura, acredita-se que os micronutrientes $\mathrm{B}, \mathrm{Cu}, \mathrm{Fe}$, $M n$ e $Z n$ não sejam limitantes para um bom crescimento da vegetação arbórea nativa da floresta estudada. Ainda conforme Marschner (1986), os micronutrientes desempenham várias funções fisiológicas importantes nas plantas, os quais, além do crescimento, manifestamse em vários processos fenológicos das plantas, como floração, frutificação, propagação, proteção contra pragas e doenças, entre outros.

$\mathrm{Na}$ Tabela 3, pode-se visualizar que os micronutrientes estocaram-se na biomassa em quantidades relativamente pequenas, de acordo com os seus teores, destacando-se o Mn e o Fe, com 45,62 \% e 38,9l \%, respectivamente. Nos galhos e na madeira estão os maiores estoques de micronutrientes, em razão da sua maior biomassa, resultando na seguinte ordem de grandeza: Galhos $>$ Madeira > Casca > Folhas. Segundo Gonçalves e Valeri (200I), para a maioria dos micronutrientes, é na madeira que se encontram os maiores estoques, simplesmente por causa de sua elevada biomassa. No presente estudo, - Manganês é o micronutriente armazenado em maior quantidade na biomassa (Tabela 3), seguido pelo Ferro, Zinco, Boro e Cobre.

Brun et al. (2010) encontrou em uma Floresta Estacional Decidual Secundária com cerca de 53 anos, em Santa Tereza-RS, um estoque de micronutrientes bastante próximo aos valores observados neste trabalho, sendo eles de, $2,54 \mathrm{~kg} \cdot \mathrm{ha}^{-1}$ de B, I,09 $\mathrm{kg} \cdot \mathrm{ha}^{-1}$ de Cu, 27,9l $\mathrm{kg} \cdot \mathrm{ha}^{-1}$ de Fe, 23,96 kg.ha-1 de Mn e 4,34 kg.ha-1 de Zn. Caldeira et al. (2006) encontrou a maioria dos nutrientes armazenados nos galhos em uma Floresta Ombrófila Mista Montana em General Carneiro/PR. Esses autores atribuem esse resultado por considerarem como galhos todo o material lenhoso localizado acima do início da copa viva, o que pode gerar uma relativa superestimação da biomassa de galhos e uma subestimação da biomassa de troncos, com o mesmo comportamento para a quantidade de nutrientes acumulados, uma vez que, geralmente, os teores nutricionais da madeira são inferiores aos dos galhos vivos.
TABELA 3 Estoque de micronutrientes na biomassa acima do solo das árvores e sua participação relativa por componente, na Floresta Estacional Decidual em Itaara-RS, Brasil.

TABLE 3 Micronutrients stock in above ground biomass of trees and their relative distribution in the components in a Seasonal Subtropical forest in Itaara-RS, Brazil.

\begin{tabular}{|c|c|c|c|c|c|c|}
\hline \multicolumn{7}{|c|}{ Nutrientes $\left(\mathrm{kg} \cdot \mathrm{ha}^{-1}\right)$} \\
\hline & $B$ & $\mathrm{Cu}$ & $\mathrm{Fe}$ & $\mathrm{Mn}$ & $\mathrm{Zn}$ & Total \\
\hline \multirow{2}{*}{ Madeira } & 0,45 & 0,27 & 4,52 & 4,46 & 4,36 & \multirow{2}{*}{14,06} \\
\hline & $(0,76)^{*}$ & $(0,46)$ & $(7,64)$ & $(7,54)$ & $(7,36)$ & \\
\hline \multirow{2}{*}{ Casca } & 0,18 & 0,08 & 3,49 & 1,81 & 0,23 & \multirow{2}{*}{5,79} \\
\hline & $(0,31)$ & $(0,13)$ & $(5,90)$ & $(3,07)$ & $(0,39)$ & \\
\hline \multirow{2}{*}{ Galhos } & 1,20 & 0,71 & 14,01 & 18,93 & 1,38 & \multirow{2}{*}{36,23} \\
\hline & $(2,03)$ & $(1,20)$ & $(23,69)$ & $(32,01)$ & $(2,34)$ & \\
\hline \multirow{2}{*}{ Folhas } & 0,15 & 0,04 & 1,00 & 1,78 & 0,10 & \multirow{2}{*}{3,07} \\
\hline & $(0,26)$ & $(0,07)$ & $(1,69)$ & $(3,01)$ & $(0,17)$ & \\
\hline \multirow{2}{*}{ Total } & 1,98 & 1,10 & 23,01 & 26,98 & 6,07 & \multirow{2}{*}{59,14} \\
\hline & $(3,35)$ & $(1,86)$ & $(38,91)$ & $(45,62)$ & $(10,26)$ & \\
\hline
\end{tabular}

Apesar de sua relativa pequena quantidade na biomassa, o conhecimento do estoque dos micronutrientes é de grande importância para a manutenção da fertilidade do solo e nutrição das árvores, sendo imprescindível nos estudos de balanço nutricional nos ecossistemas.

Esses resultados apontam a importância de se conhecer a dinâmica dos micronutrientes nas florestas nativas, e as possíveis consequências de eventuais perturbações que possam ocorrer nessas florestas, como, por exemplo, o corte de árvores, sendo de grande importância a permanência, principalmente dos galhos, folhas e cascas, sobre o solo, onde está estocada a maior parte desses micronutrientes, minimizando, dessa maneira, a exportação de nutrientes para fora do sítio.

\section{CONCLUSÕES}

A produção total estimada de biomassa acima

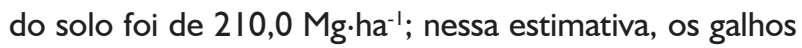
corresponderam a 48,8\%, a madeira do fuste $43,3 \%$, a casca do fuste $5,4 \%$, e as folhas $2,4 \%$;

Os menores teores de B, Cu, Fe e $\mathrm{Mn}\left(\mathrm{mg} \cdot \mathrm{kg}^{-1}\right)$ estão na madeira do fuste, com exceção do $\mathrm{Zn}$;

Nos galhos seguidos da madeira, estão os

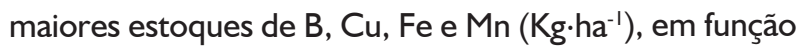
de sua maior biomassa;

O Manganês é o micronutriente armazenado em maior quantidade na biomassa, seguido pelo Ferro, Zinco, Boro e Cobre; 
Nos galhos, folhas e cascas está estocada a maior parte dos micronutrientes, apontando a importância destes de permanecerem sobre o solo, frente a uma eventual perturbação, como, por exemplo, o corte raso da floresta; nesse caso deve-se retirar somente a madeira, permanecendo todos os resíduos da colheita sobre o solo.

\section{AGRADECIMENTOS}

À Capes, pela bolsa de estudos de doutorado no Brasil, e o DAAD pela bolsa de estudos na Alemanha.

Os autores agradecem também à Brigada Militar do Estado do Rio Grande do Sul por ceder a área em que foi realizado o presente estudo, localizada no Centro de Estudos e Treinamento, Reprodução Animal e Proteção Ambiental (CETRAPA) pertencente à Fundação da Brigada Militar no município de Itaara-RS.

\section{REFERÊNCIAS}

BARICHELLO, L. R. Quantificação da biomassa e dos nutrientes em floresta de Acacia mearnsii De Wild. na região sul do Brasil. 2003. 58 p. Dissertação (Mestrado em Silvicultura) - Universidade Federal de Santa Maria, Santa Maria, 2003.

BOEGER, M. R. T.; WISNIEWSKI, C.; REISSMANN, C. B. Nutrientes foliares de espécies arbóreas de três estádios sucessionais de Floresta Ombrófila Densa no Sul do Brasil. Acta Botânica Brasílica, Porto Alegre, v. 19, n. I, p. I67I8I, 2005.

BROWN, S. Estimating biomass and biomass change of tropical forest: a primer. Rome: FAO, 1997. 55 p. (Forestry Paper, 134).

BROWN, S.; GILLESPIE, A. J. R.; LUGO, A. E. Biomass of tropical forests of south and southeast Asia. Canadian Journal of Forest Research, Ottawa, v. 21, p. III-117, 1991.

BRUN, E. J. Biomassa e nutrientes na floresta Estacional Decidual, em Santa Tereza, RS. 2004. I 36 p. Dissertação (Mestrado em Silvicultura) - Universidade Federal de Santa Maria, Santa Maria, 2004.

BRUN, E. J.; BRUN, F. G. K.; CORRÊA, R. S.; VACCARO, S.; SCHUMACHER, M. V. Dinâmica de micronutrientes na biomassa florestal em estágios sucessionais de Floresta Estacional Decidual, RS, Brasil. Scientia Forestalis, Piracicaba, v. 38, n. 86, p. 307-3I8, jun. 2010.

CALDEIRA, M. V. W. Determinação de biomassa e nutrientes em uma floresta Ombrófila Mista Montana em General Carneiro, Paraná. 2003. 176 p. Tese (Doutorado em Engenharia Florestal) - Universidade Federal do Paraná, Curitiba, 2003.
CALDEIRA, M. V. W.; WATZLAWICK, L. F.; SOARES, R. V.; VALÉRIO, A. F. Teores de micronutrientes em espécies arbóreas da Floresta Ombrófila Mista Montana: General Carneiro, PR. Ambiência, Guarapuava, v. 2, n. I, p. 2950, 2006.

EMPRESA BRASILEIRA DE PESQUISA AGROPECUÁRIA. Centro Nacional de Pesquisa de Solos. Sistema brasileiro de classificação de solos. Rio de Janeiro, 1999. 412 p.

FINGER, C. A. G. Fundamentos de biometria florestal. Santa Maria: UFSM/CEPEF/FATEC, 1992. 269 p.

FLOSS, E. L. Fisiologia das plantas cultivadas: o estudo do que está por trás do que se vê. Passo Fundo: UPF, 2008. $733 \mathrm{p}$.

GOLLEY, F. B.; MCGINNIS, J. T.; CLEMENTS, R. G.; CHILD, G. L.; DUEVER, M. J. Ciclagem de minerais em um ecossistema de floresta tropical úmida. São Paulo: EPU, 1978. 256 p.

GONÇALVES, J. L. M.; VALERI, S. V. Adubos e adubações: eucalipto e pinus. In: FERREIRA, M. E.; CRUZ, M. C. P.; RAIJ, B.; ABREU, C. A. (Ed.). Micronutrientes e elementos tóxicos na agricultura. Jaboticabal: CNPq/ FAPESP/POTAFOS, 200I. p. 393-423.

HIGUCHI, N.; SANTOS, J.; RIBEIRO, R. J.; MINETTE, L.; BIOT, Y. Biomassa da parte aérea da vegetação da floresta tropical úmida de terra firme da Amazônia brasileira. Acta Amazônica, Manaus, v. 28, n. I, p. I53-166, 1998.

KRAMER, R. J.; KOSLOWSKI, T. T. Fisiologia das árvores. Lisboa: Fundação Kalouste Gouldbenkian, 1972. 745 p.

LANDSBERG, J. J. Physiological ecology of forest production. London: Academic, 1986. 198 p.

LARCHER, W. Ecofisiologia vegetal. São Carlos: RiMa Artes e Textos, 2000. 531 p.

MALAVOLTA, E. Absorção e transporte de íons e nutrição mineral. In: FERRI, M. G. (Ed.). Fisiologia vegetal I. São Paulo: EPU, 1985. p. 77-II6.

MARSCHNER, $H$. Mineral nutrition in higher plants. London: Academic, 1986. 674 p.

MIYAZAWA, M.; PAVAN, M. A.; MURAOKA, T. Análises químicas de tecido vegetal. In: SILVA, F. C. (Org.). Manual de análises químicas de solos, plantas e fertilizantes. Brasília: EMBRAPA Comunicação para Transferência de Tecnologia, 1999. p. I7I-224.

ODUM, E. P.; BARRETT, G. W. Fundamentos de ecologia. São Paulo: Cengage Learning, 2008. 612 p.

OTTO, H. J. Waldökologie. Stuttgart: Ulmer, I994. 391 p.

SILVEIRA, P.; KOEHLER, H. S.; SANQUETTA, C. R.; ARCE, J. E. $O$ estado da arte na estimativa de biomassa e carbono em formações florestais. Revista Floresta, Curitiba, v. 38, n. I, p. 185-206, 2008. 
SOCHER, L. G.; RODERJAN, C. V.; GALVÃO, F. Biomassa aérea de uma foresta ombrófla mista aluvial no município de Araucária (PR). Revista Floresta, Curitiba, v. 38, n. 2 , p. 245-252, 2008.

STRECK, E. V.; KÄMPF, N.; DALMOLIN, R. S. D.; KLAMT, E.; NASCIMENTO, P. C.; SCHNEIDER, P.; GIASSON, E.; PINTO, L. F. S. Solos do Rio Grande do Sul. Porto Alegre: EMATER/RS, 2008. 222 p.
TEDESCO, M. J.; GIANELLO, C.; BISSANI, C. A.; BOHNEN, H.; VOLKWEISS, S. J. Análise de solo, plantas e outros materiais. Porto Alegre: UFRGS, 1995. 174 p. (Boletim Técnico, 5).

WATZLAWICK, L. F; CALDEIRA, M. V. W.; VIERA, M.; SCHUMACHER, M. V.; GODINHO, T. O.; BALBINOT, R. Estoque de biomassa e carbono na Floresta Ombrófila Mista Montana Paraná. Scientia Forestalis, Piracicaba, v. 40 , n. 95, p. 353-362, set. 2012. 